\title{
Modelo matemático para otimizar a localização de aeronaves para combate a incêndios florestais
}

\author{
Mathematical model to optimize the location of aircraft for wildfire combat
}

\author{
João António Zeferino', Ricardo José RosaII
}

\begin{abstract}
Resumo
Os incêndios florestais são uma preocupação crescente e uma ameaça constante aos seres humanos, às florestas e aos seus ecossistemas. Com as alterações climáticas há um aumento na suscetibilidade de incêndios florestais, com maior probabilidade de serem mais frequentes e alcançarem maiores dimensões. A sustentabilidade da floresta, como bem estratégico de um país, requer o planeamento e gestão de forças de proteção e socorro que possam defender eficientemente a floresta, mas também a população e o meio ambiente. Em particular, as ações iniciais de combate a incêndios são cruciais para extinguir as ocorrências em um curto espaço de tempo, enquanto são de pequenas dimensões, mas o seu sucesso depende de vários fatores, incluindo as características das aeronaves e a sua distância até aos locais de incêndio. Portanto, é imprescindível que esses recursos estejam estrategicamente localizados. Este trabalho pretende desenvolver um modelo matemático de otimização para a localização de aeronaves de combate a incêndios florestais. O modelo visa encontrar uma solução para a localização das diferentes aeronaves que maximizem a cobertura de acordo com os níveis de perigosidade de incêndio das diferentes áreas de uma região. O modelo é resolvido através de métodos gerais de resolução providenciados pelo software comercial FICO Xpress. A sua potencial aplicabilidade é validada através da apresentação detalhada de um estudo de caso de Portugal.
\end{abstract}

Palavras-chave: Modelo de otimização; Fogos; Combate aéreo

\begin{abstract}
Forest fires are a growing concern and a constant threat to humans, to forests and to their ecosystems. Along with climate change there is an increase in the susceptibility of wildfires, with a higher likelihood of them being more frequent and reaching larger dimensions. The sustainability of the forests, as strategic assets of a country, requires the planning and management of protection and relief forces that can efficiently defend the forest, but also the population and the environment. In particular, the initial firefighting actions are crucial to extinguish the occurrences in a short time while they are of small dimensions. But their success depends on several factors, including the aircraft characteristics and their distance to the fire locations. Therefore, it is imperative that these resources are strategically located. This work intends to develop a mathematical optimization model for the location of aircraft for wildfire combat. The model aims to find a solution for the location of the different aircraft that maximize the coverage according to the fire hazard levels of the different areas within a region. The model is solved through general resolution methods provided by FICO Xpress commercial software. Its potential applicability is validated through the detailed presentation of a case study from Portugal.
\end{abstract}

Keywords: Optimization model; Forest fires; Aerial firefighting

\footnotetext{
Engenheiro Civil, PhD., Centro de Investigação do Território, Transportes e Ambiente (CITTA), Professor do Departamento de Engenharia Civil, Universidade de Coimbra, Polo II, CEP 3030-788, Coimbra, Portugal. zeferino@dec.uc.pt (ORCID: 0000-0002-9482-8540)

II Engenheiro Civil, Departamento de Engenharia Civil, Universidade de Coimbra, Polo II, CEP 3030-788, Coimbra, Portugal. ricardo90@gmail.com (ORCID: 0000-0003-4618-5381)
} 


\section{Introdução}

Os incêndios florestais são uma preocupação cada vez maior para as populações e seus governantes, sendo uma ameaça constante aos seres humanos, às florestas e aos seus ecossistemas. Entende-se por incêndio florestal aquele que atinge uma área florestal, ou seja, uma área que se encontra arborizada ou inculta. O problema dos incêndios florestais é de escala mundial atingindo, consoante as estações do ano, os diversos continentes como: a África Central e do Sul, a Ásia, o Norte da Oceania, todo o Continente Americano, em particular, as zonas centrais do Brasil, e também o Sul da Europa. Os Países Mediterrâneos são locais com grande ocorrência de incêndios, incluindo Portugal que ocupa o primeiro lugar na Europa em relação ao número total de ocorrências de incêndios e à área queimada ao longo dos últimos anos (SANMIGUEL-AYANZ et al., 2017).

Atualmente, com as alterações climáticas, verifica-se um aumento na suscetibilidade de incêndios florestais, com maior probabilidade de serem mais frequentes e alcançarem maiores dimensões. Em 2016 verificou-se um novo valor máximo para a temperatura média global no Planeta, cerca de $1,0^{\circ} \mathrm{C}$ acima da média do século XX. No caso de Portugal, apesar de o número de ocorrências de incêndios florestais registadas em 2016 ter sido inferior à média da década precedente, a área queimada duplicou relativamente à respectiva média. Em 2017, após elevadas temperaturas e uma seca prolongada, a área queimada foi ainda superior, atingindo cerca de $12 \%$ da área florestal, resultando na destruição de milhares de edificações, principalmente de casas destinadas à habitação e seus edifícios anexos, e na perda de mais de uma centena de vidas humanas. Em Portugal, assim como de uma forma global, o desenvolvimento de políticas e mecanismos de prevenção e combate aos incêndios florestais é essencial, sobretudo tendo em conta o seu potencial agravamento futuro.

A preocupação com o combate aos incêndios florestais deve ter principal incidência em locais onde exista maior perigo de incêndio. O perigo de incêndio depende da probabilidade e suscetibilidade de ocorrência de um incêndio em uma determinada área, sendo denominado como perigosidade de incêndio. O risco de incêndio associado dependerá da perigosidade e do dano potencial, que requer o conhecimento da vulnerabilidade e valor económico. Um determinado território é influenciado a ter um certo nível de perigosidade de acordo com vários fatores como: o tipo de vegetação, a altimetria, o relevo, o número de dias de temperatura elevada, a precipitação média, os registos históricos de incêndios, entre outros (VERDE, 2008). Os Sistemas de Informação Geográfica (SIG) permitem manipular, analisar, modelar e gerir grandes quantidades de dados espaciais, tendo grande potencial para lidar com questões de ordenamento do território, assim como na oferta de um apoio à tomada de decisão (MALCZEWSKI, 2004; ZHANG; LI; FUNG, 2012). Neste sentido, através de SIG é possível avaliar os diferentes fatores de perigosidade de incêndio e produzir cartas de perigosidade de incêndio de âmbito regional ou nacional (BATISTA et al., 2014; CHUVIECO et al., 2010; VERDE; ZÊZERE, 2010).

Os meios aéreos têm um papel preponderante no combate aos incêndios florestais dada a celeridade com que se dirigem a um local de ocorrência e a grande quantidade de água que transportam, permitindo diminuir de forma mais eficiente a massa térmica de um incêndio. Além de poderem ser facilmente abastecidos de água, devido ao elevado número de pontos de água a que podem aceder, têm a possibilidade de alcançar locais de combate onde, por vezes, não é possível o acesso terrestre. Diferentes tipos de aeronaves podem ser utilizadas de acordo com o tipo de missão a executar, denominadas de helicópteros bombardeiros (HEB) e aviões bombardeiros (AVB), os quais se podem ainda classificar em ligeiros, médios ou pesados, consoante a capacidade de água a transportar. Um dispositivo aéreo de combate a incêndios encontra-se limitado pelos tipos de aeronaves disponíveis, mas também pelos centros de meios aéreos em que estas podem ser localizadas. Os centros de meios aéreos correspondem às bases aéreas onde as aeronaves ficam estacionadas, mas acomodam também os pilotos, as equipes helitransportadas e o restante apoio a todas as operações. Os meios aéreos são particularmente úteis no ataque inicial (ATI), 
que é uma ação preponderante na eficiência do combate a incêndios florestais, visando extinguir as ocorrências em um curto espaço de tempo, enquanto são de pequenas dimensões. O sucesso do ATI leva a uma redução das áreas queimadas, mas está dependente de vários fatores relativos às especificidades das aeronaves, tais como as capacidades de descarga, as distâncias e os tempos de viagem até aos incêndios. Neste sentido, a localização dos diferentes tipos de aeronaves deve ser alvo de um planeamento estratégico adequado, dada a sua relevância na eficácia do ATI e respetivo combate a incêndios florestais.

O problema da localização ótima das aeronaves de combate a incêndios, entre um conjunto de possíveis bases aéreas, enquadra-se em problemas da maximização da cobertura, pretendendo-se assegurar o máximo de cobertura da perigosidade de incêndio existente numa dada região. Desde os anos 60, modelos de otimização começaram a ser desenvolvidos para a localização de equipamentos de emergência, como esquadras de polícia (HAKIMI, 1964) ou quartéis de bombeiros (TOREGAS et al., 1970). Neste contexto surgiu na literatura uma linha de investigação dedicada ao problema da localização de equipamentos. O problema da localização de equipamentos é normalmente classificado em três categorias, dependendo do objetivo que se pretende otimizar: maximizar a acessibilidade ou minimizar os custos de transporte para um determinado número de equipamentos (DANTRAKUL; LIKASIRI; PONGVUTHITHUM, 2014); minimizar os custos totais de transporte e implementação dos equipamentos (MILLER et al., 2013); ou maximizar a cobertura proporcionada pelos equipamentos (ZHANG; PENG; LI, 2017). Diferentes abordagens de otimização têm sido usadas para lidar com problemas relacionados com o combate a incêndios florestais, em particular na escolha e operação dos meios de combate a utilizar. Bookbinder e Martell (1979) desenvolveram um modelo de otimização baseado na teoria da fila de espera para o helitransporte de equipes para os incêndios. Donovan e Rideout (2003) e Snyder, Stockmann e Morris (2012) desenvolveram modelos de apoio à gestão financeira das operações de despacho e dos contratos de aquisição dos meios aéreos, respectivamente. Modelos essencialmente focados na fase operacional do combate foram desenvolvidos por MartinFernández, Martínez-Falero e Pérez-González (2002), para o despacho ótimo de diferentes meios de combate, incluindo uma simulação dos riscos de incêndios associados; e por Ntaimo et al. (2012), para a localização e despacho ótimos de buldózeres, tendo em conta riscos associados a registos históricos de incêndios.

O objetivo deste trabalho foi desenvolver um modelo de otimização para a localização de aeronaves na fase estratégica do combate a incêndios florestais, garantindo a máxima cobertura das florestas, em termos da perigosidade de incêndio previamente definida e adaptada.

\section{Material e métodos}

\section{Modelo de otimização}

O modelo de otimização desenvolvido pretende encontrar uma solução ótima para a localização das diferentes aeronaves, com diferentes especificidades, a qual maximize a cobertura de acordo com os níveis de perigosidade de incêndio das diferentes áreas de uma região. O modelo necessita levar em conta as bases aéreas disponíveis e as respectivas distâncias às diferentes áreas com perigosidade de incêndio. Além disso, são consideradas as aeronaves que podem ser usadas, assim como as suas características. Restrições adicionais permitem garantir a cobertura de certos níveis de perigosidade e definir o número máximo de aeronaves a implementar em cada base.

Em seguida é apresentada a notação usada e a formulação do modelo.

Conjuntos:

$\boldsymbol{J}=$ conjunto de centros representativos das áreas com perigosidade de incêndio;

$\boldsymbol{K}=$ conjunto de sítios (bases aéreas) onde as aeronaves estão localizadas; 
$\boldsymbol{L}=$ conjunto dos tipos de aeronaves existentes.

Variáveis de decisão:

$y_{k l}=$ número de aeronaves do tipo $l$ localizadas no sítio $k$;

$x_{i k l}=$ nível de perigosidade do centro $j$ coberta por aeronaves do tipo $l$ localizadas em $k$.

Parâmetros:

$c_{l}=$ capacidade normalizada das aeronaves do tipo $l$;

$d r_{j k l}=$ variável auxiliar de penalização da distância entre o centro $j$ e o sítio $k$, para cada aeronave do tipo $l$;

$r_{j}=$ nível de perigosidade correspondente ao centro $j$;

ro = nível de perigosidade que requer cobertura obrigatória; do tipol;

$s_{j k l}=$ variável auxiliar de irradiação máxima entre o centro $j$ e o sítio $k$, para cada aeronave

$n_{k}=$ número máximo de aeronaves permitidas em cada base aérea $k$;

$p_{l}=$ número máximo de aeronaves do tipo $l$ que estão disponíveis;

$d_{j k}=$ distância entre o centro $j$ e o sítio $k$;

$d \max _{l}=$ raio máximo que pode ser coberto por uma aeronave do tipo $l$.

O modelo tem como função objetivo:

Maximizar $U=\sum_{j \in J} \sum_{k \in K} \sum_{l \in L} x_{j k l} \cdot c_{l} \cdot d r_{j k l}$

Sujeito a:

$x_{j k l} \leq r_{j} \cdot y_{k l} \cdot s_{j k l}, \quad \forall j \in J, k \in K, l \in L$

$\sum_{k \in K} \sum_{l \in L} x_{j k l} \geq r_{j}, \forall j \in J \mid r_{j} \geq r o$

$\sum_{l \in L} y_{k l} \leq n_{k}, \forall k \in K$

$\sum_{k \in K} y_{k l} \leq p_{l}, \forall l \in L$

$d r_{j k l}=1-d_{j k} /\left(2 \cdot d \max _{l}\right), \forall j \in J, k \in K, l \in L$

$s_{j k l}=\left\{\begin{array}{l}1 \mid d_{j k} \leq \operatorname{dmax}_{l} \\ 0 \mid d_{j k}>d \max _{l}\end{array}, \quad \forall j \in J, k \in K, l \in L\right.$

$x_{j k l} \geq 0, \forall j \in J, k \in K, l \in L$

$y_{k l} \in \mathbb{N}_{0}, \forall k \in K, l \in L$

A função objetivo (1) consiste na maximização da cobertura da perigosidade tendo em conta as características das aeronaves e a distância desde os sítios onde elas estão localizadas. Assim, a cobertura de perigosidade na região é tanto maior quanto maior for a capacidade das aeronaves usadas, e é menor quanto mais distante estiver a área de perigosidade da base aérea onde está localizada a aeronave. $\mathrm{O}$ valor de $c_{l}$ representa uma capacidade normalizada das aeronaves, de forma aos seus valores serem da mesma ordem de grandeza das restantes variáveis 
da função objetivo, tal como sucede com o valor de $d r_{i k l}$, que representa uma penalização devida ao afastamento da aeronave.

A restrição (2) define a cobertura do centro $j$, cuja perigosidade é coberta por aeronaves do tipo $l$ que estejam localizadas no sítio $k$ se a distância entre $j$ e $k$ for menor do que o raio máximo de cobertura para esse tipo de aeronave. A restrição (3) garante que para os centros que possuam um nível de perigosidade acima do nível que requer cobertura obrigatória, a perigosidade total coberta em cada centro $j$ é pelo menos superior ao nível de perigosidade desse centro. Caso o nível de perigosidade que requer cobertura obrigatória seja definido como nulo, isso significará que todos os centros sejam cobertos. A restrição (4) expressa o número máximo de aeronaves em cada sítio $k$. A restrição (5) limita o número máximo de aeronaves de cada tipo $l$ que estão disponíveis para serem usadas. A restrição (6) define a penalidade, $d r_{j k}$, usada na função objetivo. A cobertura de perigosidade de uma aeronave do tipo $l$ é total caso o centro $j$ e a base aérea $k$ sejam coincidentes, mas vai reduzindo até um mínimo de metade à medida que a distância entre eles aumenta A restrição (7) é a restrição que permite definir a irradiação máxima, fazendo, em conjunto com a restrição (2), com que uma aeronave em $k$ só possa efetuar a cobertura sobre um centro $j$ caso esteja a uma distância inferior ao seu raio máximo de cobertura. As restrições (8) e (9) definem o domínio das variáveis de decisão.

O modelo desenvolvido é do tipo linear, dado que todas as funções são lineares, e uma vez que possui variáveis inteiras e mistas, recorre à otimização combinatória mista. Para a sua resolução são usados métodos gerais providenciados pelo software comercial FICO Xpress. A sua potencial aplicabilidade é demonstrada através da apresentação dos resultados de um estudo de caso, como apresentado em seguida.

\section{Estudo de caso}

O modelo proposto foi testado em um estudo de caso em Portugal. Como referido anteriormente, Portugal é um dos países mais afetados por incêndios florestais na Europa, além de possuir uma das maiores proporções de áreas florestais na Europa, cerca de 36\%, correspondente a 3.1 milhões ha. Em Portugal, o planeamento dos meios de ação, nomeadamente das aeronaves e respetivo conjunto de possíveis bases aéreas, é anualmente definido pelo Dispositivo Especial de Combate a Incêndios Florestais de forma a cumprir os objetivos estratégicos definidos pelo Governo (COMANDO NACIONAL DE OPERAÇÕES DE SOCORRO, 2017). Contudo, não existe qualquer normativa ou base operativa usada na definição da localização dos meios aéreos, não sendo essa localização alvo de qualquer tipo de otimização, quer na fase estratégica quer na fase operacional de despacho dos meios. Portanto, em Portugal, tal como em diversas regiões no mundo, o desenvolvimento de uma metodologia que defina de forma otimizada a localização dos meios aéreos é pertinente, de forma a melhorar a eficácia do ATI e reduzir os efeitos nefastos dos incêndios florestais.

Em seguida são apresentadas as características do território Português em termos da perigosidade de incêndio, assim como das aeronaves e das bases aéreas disponíveis para implementação do dispositivo de combate a incêndios. Posteriormente, com base na carta de perigosidade de incêndio, é apresentado um método para definição da perigosidade simplificada através de um conjunto de nós representativos.

\section{Características do estudo de caso}

Verde e Zêzere (2010) definiram, com base em diferentes fatores, uma carta de perigosidade de incêndio florestal para Portugal, a qual é anualmente atualizada e disponibilizada através do Instituto da Conservação da Natureza e das Florestas (2017). Os níveis de perigosidade são definidos com base em seis classes: nula, muito baixa, baixa, média, alta e muito alta. Na Figura 
1a é apresentada a carta de perigosidade de incêndio florestal referente a 2017.

O dispositivo de meios aéreos portugueses para combate a incêndios é composto por aeronaves permanentes e contratadas. O número de aeronaves e a sua localização durante cada ano é estabelecido considerando 5 diferentes Fases, ou seja, períodos temporais: Alfa, Bravo, Charlie, Delta e Echo. Em cada período, o estado de alerta é diferente e, portanto, diverge o número de aeronaves utilizadas. A Fase Charlie, com vigência desde o dia 1 de julho até ao dia 30 de setembro de cada ano, corresponde à temporada de maiores temperaturas e menor precipitação, sendo por isso a mais crítica de incêndios e a que envolve mais meios aéreos. Em 2017, na Fase Charlie foram disponibilizadas 47 aeronaves, as quais são classificadas em função da sua capacidade de água e raio de cobertura. Na Tabela 1 são apresentados os 5 tipos de aeronaves consideradas e as suas características. No caso dos AVB, são considerados pares de aviões como apenas um único meio, pois estas duplas são normalmente indissociáveis. Desta forma, a sua capacidade é duplicada.

Tabela 1 - Resumo dos diferentes tipos de aeronaves e suas características.

Table 1 - Summary of the different types of aircraft and their characteristics.

\begin{tabular}{cccccc}
\hline \multicolumn{1}{c}{ Tipo de aeronave } & $l$ & $p_{l}$ & $\begin{array}{c}\text { Capac. } \\
(\text { litros })\end{array}$ & $\begin{array}{c}\text { Capac. } \\
\text { Norm. }\end{array}$ & $\begin{array}{c}\text { Raio } \\
(\mathbf{k m})\end{array}$ \\
\hline Helicóptero Bombardeiro Ligeiro (HEBL) & 1 & 28 & 900 & 0,50 & 40 \\
Helicóptero Bombardeiro Médio (HEBM) & 2 & 8 & 1200 & 0,51 & 40 \\
Helicóptero Bombardeiro Pesado (HEBP) & 3 & 3 & 4000 & 0,65 & 70 \\
Avião Bombardeiro Médio (AVBM) & 4 & 3 & $2 * 3200$ & 0,76 & 120 \\
Avião Bombardeiro Pesado (AVBP) & 5 & 1 & $2^{\star} 5750$ & 1,00 & 120 \\
\hline
\end{tabular}

Em que: $l$ = parâmetro do modelo referente ao tipo de aeronave; $p_{l}=$ parâmetro do modelo referente ao número de aeronaves disponíveis.

Em Portugal existem 49 potenciais bases aéreas onde os HEB, os AVB e respetivo apoio a todas as operações podem estar estacionados e preparados para o combate a incêndios, estando posicionadas no território como apresentado na Figura 1b. As bases aéreas do tipo heliporto permitem apenas a localização de HEB e as do tipo aeródromo permitem a localização de qualquer tipo de aeronave. Como referido anteriormente, as localizações das aeronaves entre as potenciais bases aéreas são anualmente definidas, para cada período temporal, não sendo, porém, usado qualquer modelo de otimização para o efeito, em particular tendo em conta a perigosidade de incêndio existente em cada área.

\section{Definição da perigosidade simplificada}

A perigosidade de incêndio em uma certa região, ou ao nível de um país como o caso de Portugal, é frequentemente estimada e disponibilizada apenas em formato raster, ou seja, formada por um conjunto de pixels representativos de diferentes classes de perigosidade, como é o caso da carta de perigosidade com seis classes ilustrada na Figura 1a. Este formato é adequado para abordagens de planeamento elaboradas através de SIG, mas impossibilita o uso de abordagens de otimização devido ao elevado número de dados. Desta forma, é necessário encontrar pontos representativos, centroides, que reproduzam a média de perigosidade em seu redor, permitindo assim diminuir a quantidade de dados a analisar e tratar.

Com base na carta de perigosidade de incêndio florestal referente a 2017 foi criada através de um software SIG uma grade com espaçamento de $10 \mathrm{~km}$, na qual se definiram centroides 
representativos das áreas contidas em cada quadrícula (Figura 1a). Após excluídos os casos que não se encontrassem maioritariamente dentro do território de Portugal, obteve-se um total de 895 centroides. Com recurso ao software SIG foi calculado o nível de perigosidade média ponderada da quadrícula respectiva a cada centroide, finalizando assim a conversão do formato raster inicial para o conjunto de centros $j$ a usar posteriormente no modelo de otimização. A respectiva carta de perigosidade média encontra-se ilustrada na Figura $1 \mathrm{~b}$. A cada centro $j$ corresponde um nível de perigosidade equivalente à variável $r_{j}$ do modelo de otimização, a qual varia no intervalo de 0 a 5 , correspondentes à mínima e máxima perigosidade, respectivamente.

Figura 1 - (a) Carta de perigosidade, com representação de grade; (b) Carta de perigosidade simplificada em formato grade.

Figure 1 - (a) Hazard map, with representation of the grid; (b) Simplified hazard map in grid format.

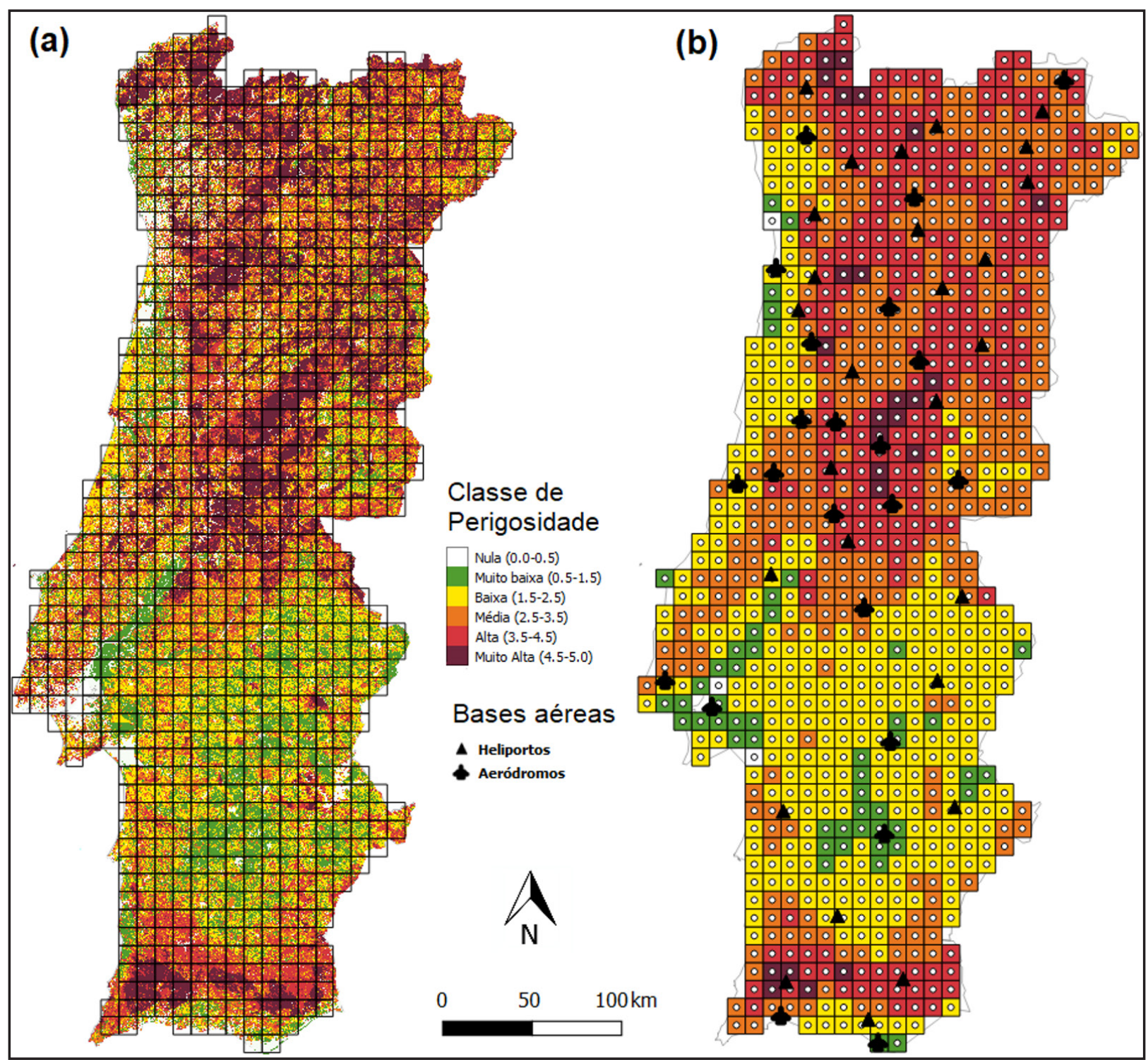

Fonte: Autores (2018) 


\section{Resultados e discussão}

Os casos estudados têm como objetivo analisar as soluções obtidas pelo modelo matemático de otimização desenvolvido, usando para tal uma comparação com a distribuição de aeronaves existente em Portugal, definida em 2017 para a Fase Charlie, a de maior perigosidade (COMANDO NACIONAL DE OPERAÇÕES DE SOCORRO, 2017). Na Figura 2 apresenta-se a distribuição de aeronaves nas diversas bases aéreas existentes na Fase Charlie de 2017, observada com recurso a SIG. A distribuição existente foi analisada de forma a aplicarem-se restrições semelhantes no modelo de otimização, permitindo assim a comparação direta entre a solução correspondente à distribuição existente e a solução obtida pelo modelo.

Na Figura 2 observa-se a existência de várias zonas na distribuição existente em 2017 que não são cobertas por qualquer tipo de aeronave. É possível deduzir através do modelo que, nessa solução correspondente à distribuição existente, o nível ro de perigosidade que requer cobertura obrigatória é de 3,0. Este parâmetro é definido e utilizado na restrição (3) do modelo. No que diz respeito ao número máximo de aeronaves por base aérea, correspondente à variável $n_{K}$ da restrição (4) do modelo, constata-se que deverá ser equivalente a 2 , significando que não podem estar mais que duas aeronaves em cada base aérea (considerando as duplas de aviões como um único meio aéreo). Outra condicionante observada relativamente ao limite de aeronaves é que não é sediada em cada base aérea mais do que uma única dupla de aviões, quer sejam AVBM ou AVBP, o que pode também ser incluído em uma restrição idêntica no modelo. Este conjunto de restrições é aplicado no denominado Caso A, cujos resultados obtidos pelo modelo se apresentam através de SIG na Figura 3a.

De forma a analisar uma solução mais restritiva, em que se tenha o intuito de garantir uma cobertura completa por aeronaves, é considerado o Caso B. Nesta situação, ao contrário do Caso A, o nível ro de perigosidade que requer cobertura obrigatória é definido como 0 sendo utilizado na restrição (3) do modelo, garantido desta forma a cobertura de todos os centros independentemente da sua perigosidade de incêndio. A solução obtida para o Caso B é apresentado na Figura 3b.

As duas soluções obtidas (Figura 3) podem ser comparadas com a distribuição de aeronaves existente em 2017 (Figura 2). Constata-se pela leitura da Figura 3a que o modelo no Caso A tende a localizar as aeronaves nas áreas mais críticas em termos de perigosidade de incêndio (interior, centro e norte). No que diz respeito à distribuição existente em 2017 há uma maior dispersão das aeronaves, apesar de alguma parte da respectiva cobertura situar-se em áreas de baixa perigosidade ou fora do território. Relativamente ao Caso B, como seria de esperar, de forma a garantir que para qualquer perigosidade todos os centros sejam cobertos por pelo menos uma aeronave, há uma maior distribuição das aeronaves de forma a garantir a cobertura da totalidade do território.

No entanto, o aspecto a salientar nestas soluções está relacionado com os níveis totais de cobertura de perigosidade. Uma vez que as duas soluções obtidas pelo modelo resultam de uma otimização, ambas maximizam a cobertura de perigosidade de acordo com as restrições consideradas. Esse valor de cobertura total de perigosidade é dado pela função objetivo definida no modelo. No caso da distribuição existente em 2017, é possível, fazendo uso do modelo, estimar o respetivo valor da função objetivo após a consideração de um conjunto de restrições que localize as aeronaves nos locais predefinidos (Figura 2). Desta forma, verifica-se que a solução obtida pelo modelo no Caso A consegue atingir uma cobertura total de perigosidade $7,4 \%$ superior relativamente à cobertura da distribuição existente em 2017. Por outro lado, no Caso B, o modelo apresenta uma cobertura total de perigosidade $0,8 \%$ superior à cobertura existente em 2017, apesar de garantir uma solução em que todo o território se encontre coberto por aeronaves mesmo nos centros com perigosidades mais baixas, ao contrário da solução existente em que apenas é garantida a cobertura de centros cuja perigosidade seja superior a 3,0 .

Segundo Hernandez et al. (2015), não é possível prever com exatidão onde e quando irão

Ci. Fl., Santa Maria, v. 29, n. 4, p. 1516-1527, out./dez. 2019 
ocorrer incêndios de grandes dimensões. A intensidade e extensão dos incêndios florestais dá origem a grandes implicações económicas, sociais e ambientais, provocando a degradação da floresta e do território e afetando diretamente a segurança das populações. Algumas causas apontadas para a problemática dos incêndios florestais são a ausência de políticas de ordenamento e gestão florestal, com o abandono de extensas áreas florestais, a ineficácia das medidas de prevenção, as condições atmosféricas adversas e as ações negligentes e criminosas (GUERREIRO et al., 2018; VIEGAS et al., 2017). Outro fator condicionante diz respeito à eficácia do combate, no qual o ataque inicial tem um papel preponderante, em particular através dos meios aéreos, os quais permitem um elevado e rápido transporte de água para as ocorrências, acedendo a zonas onde os meios terrestres não conseguem e evitando que os incêndios atinjam maiores dimensões (RODRIGUES; ALCASENA; VEGA-GARCÍA, 2019). A eficiência das aeronaves depende das suas características, da distância e do tempo de viagem até aos locais de incêndio, sendo por isso crucial que estes meios estejam estrategicamente localizados.

Figura 2 - Distribuição de aeronaves existente durante a Fase Charlie em 2017.

Figure 2 - Aircraft distribution existing during the Charlie Phase in 2017.

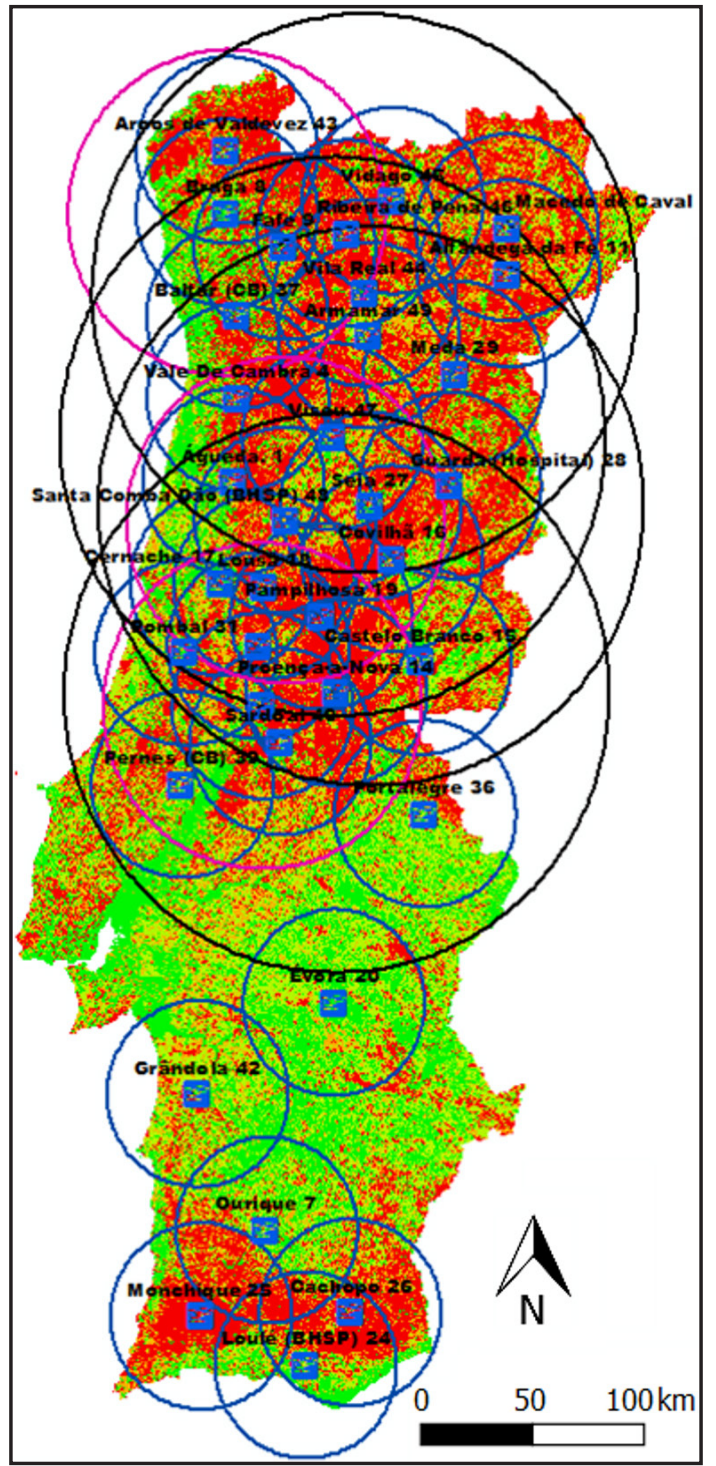

Fonte: Autores (2018) 
Figura 3 - (a) Solução obtida para o modelo no Caso A; (b) Solução obtida para o modelo no Caso B.

Figure 3 - (a) Solution obtained for the model in Case A; (b) Solution obtained for the model in Case B.

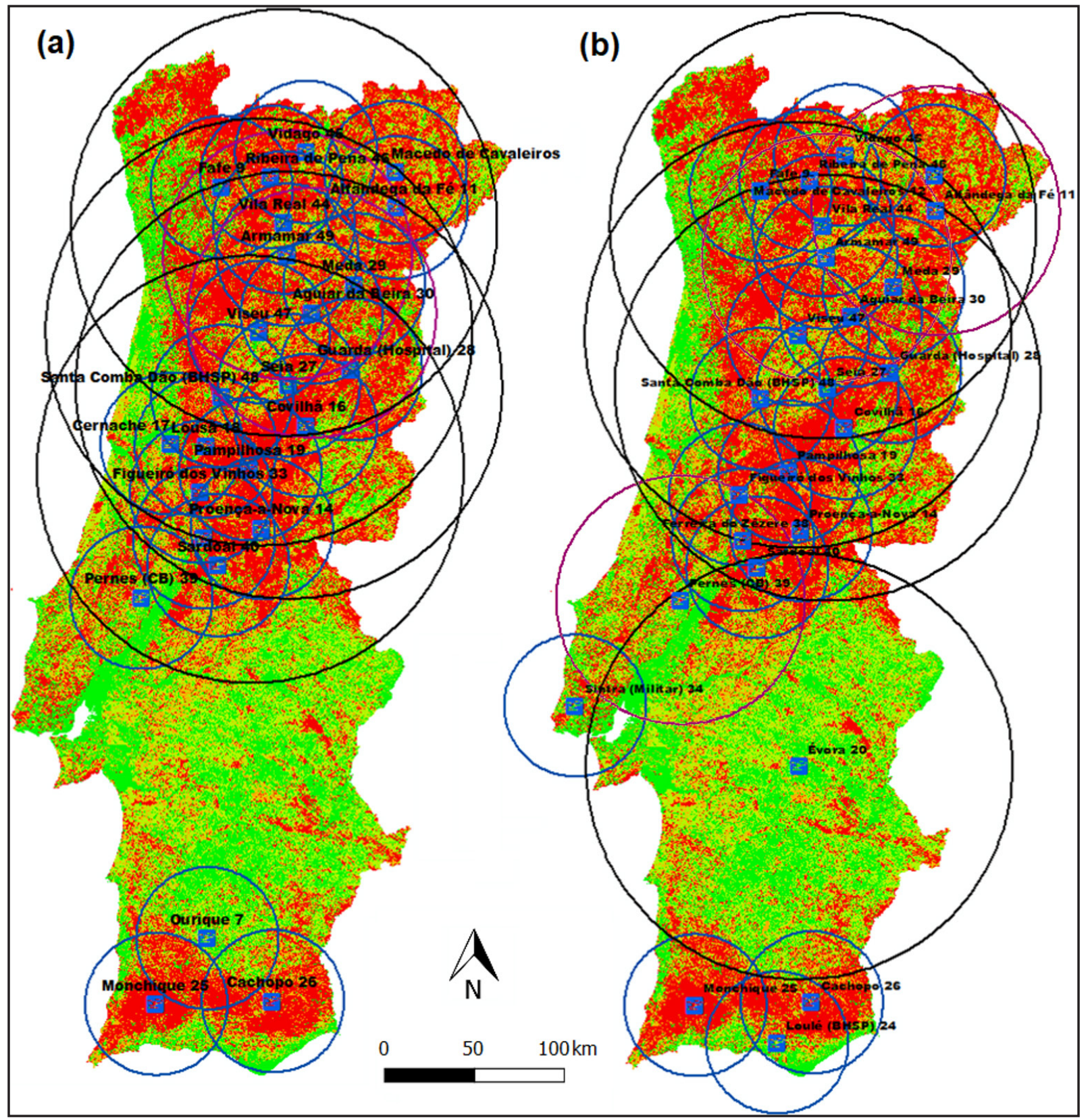

Fonte: Autores (2018)

\section{Conclusão}

O estudo de caso aplicado mostrou essencialmente que o modelo de otimização desenvolvido deverá melhorar as soluções definidas pelas autoridades competentes. Em comparação com a distribuição existente, fazendo uso do mesmo número de aeronaves e 
condicionantes, o modelo conseguiu obter uma solução com um valor de cobertura, definido em termos da função-objetivo, superior em $7,4 \%$, concentrando as aeronaves nas áreas mais críticas. Além disso, a maior vantagem neste tipo de modelo de apoio à decisão é a possibilidade de adaptar as restrições de acordo com os objetivos dos tomadores de decisão, nomeadamente em termos dos níveis de perigosidade a cobrir e do número e tipo de aeronaves a serem utilizadas. Em futuros trabalhos poderão ser analisadas potenciais localizações para bases aéreas adicionais, e a decisão poderá incidir também sobre o número de aeronaves a utilizar tendo em conta os respetivos custos. Outros potenciais melhoramentos do modelo incluem a consideração da incerteza presente neste tipo de problemas, considerando por exemplo de forma simultânea vários cenários possíveis de ocorrer no futuro, de forma a obter-se uma solução que assegure um bom desempenho.

\section{Referências}

BATISTA, A. C. et al. Análise dos impactos das mudanças climáticas sobre o risco de incêndios florestais no estado do Paraná. Scientia Forestalis, Piracicaba, v. 42, n. 104, p. 481-491, dez. 2014.

BOOKBINDER, J.; MARTELL, D. Time-Dependent Queueing Approach to Helicopter Allocation for Forest Fire Initial-Attack. INFOR: Information Systems and Operational Research, [s.l.], v. 17, n. 1, p. 58-70, fev. 1979.

CHUVIECO, E. et al. Development of a framework for fire risk assessment using remote sensing and geographic information system technologies. Ecological Modelling, [s.l.], v. 221, n.1, p. 4658, jan. 2010.

COMANDO NACIONAL DE OPERAÇÕES DE SOCORRO. Diretiva Operacional Nacional no 2 - DECIF: Dispositivo Especial de Combate a Incêndios Florestais 2017. Autoridade Nacional de Proteção Civil. Carnaxide, 2017. 130 p.

DANTRAKUL, S.; LIKASIRI, C.; PONGVUTHITHUM, R. Applied p-median and p-center algorithms for facility location problems. Expert Systems with Applications, [s.1.], v. 41, n. 8, p. 3596-3604, jun. 2014.

DONOVAN, G. H.; RIDEOUT, D. B. An integer programming model to optimize resource allocation for wildfire containment. Forest Science, [s.l.], v. 49, n. 2, p. 331-335, abr. 2003.

GUERREIRO J. et al. Relatório - Avaliação dos incêndios ocorridos entre 14 e 16 de outubro de 2017 em Portugal Continental. Comissão Técnica Independente. Assembleia da República. Lisboa, mar. 2018. 274 p.

HAKIMI, S. L. Optimum locations of switching centers and the absolute centers and medians of a graph. Operations Research, [s.1.], v. 12, n. 3, p. 450-459, 1964.

HERNANDEZ, C. et al. Statistical modelling of wildfire size and intensity: a step toward meteorological forecasting of summer extreme fire risk. Ann Geophys, [s.l.] v. 33, n. 12, p. 14951506, dez. 2015.

INSTITUTO DA CONSERVAÇÃO DA NATUREZA E DAS FLORESTAS. Avaliação da perigosidade de incêndio florestal - Classes de perigosidade para os anos. 2017. 1 mapa tif. Disponível em: <http://www2.icnf.pt/portal/florestas/dfci/inc/cartografia/cartografia-riscoclasses-perigosidade >. Acesso em: 6 jul. 2018.

MALCZEWSKI, J. GIS-based land-use suitability analysis: a critical overview. Progress in Planning, [s.1.], v. 62, n. 1, p. 3-65, jul. 2004.

MARTIN-FERNÁNDEZ, S.; MARTÍNEZ-FALERO, E.; PÉREZ-GONZÁLEZ, J. M. Optimization of the resources management in fighting wildfires. Environmental Management, New York, v. 30, n. 3, p. 352-364, 2002. 
MILLER, T. C.; FRIESZ, T. L.; TOBIN, R. L. Equilibrium facility location on networks. Springer Science \& Business Media. Berlin / New York: Springer, 2013. 244 p.

NTAIMO, L. et al. A stochastic programming standard response model for wildfire initial attack planning. Canadian Journal of Forest Research, [s.1.], v. 42, n. 6, p. 987-1001, 2012.

RODRIGUES, M.; ALCASENA, F.; VEGA-GARCÍA, C. Modeling initial attack success of wildfire suppression in Catalonia, Spain. Science of the Total Environment, [s.1.], v. 666, p. 915927, fev. 2019.

SAN-MIGUEL-AYANZ, J. et al. Forest Fires in Europe, Middle East and North Africa 2016. Joint Research Centre. Luxemburgo: Publications Office, 2017. 126 p.

SNYDER, S. A.; STOCKMANN, K. D.; MORRIS, G. E. An optimization modeling approach to awarding large fire support wildfire helicopter contracts from the US Forest Service. Forest Science, [s.l.], v. 58, n. 2, p. 130-138, fev. 2012.

TOREGAS, C. et al. The location of emergency service facilities. Operations Research, [s.1.], v. 19, n. 6, p. 1363-1373, 1970.

VERDE, J. C. Avaliação da Perigosidade de Incêndio Florestal. 2008. 97 p. Dissertação (Mestrado em Geografia Física) - Faculdade de Letras da Universidade de Lisboa, Lisboa, 2008.

VERDE, J. C.; ZÊZERE, J. L. Assessment and validation of wildfire susceptibility and hazard in Portugal. Natural Hazards and Earth System Sciences, [s.1.], v. 10, n. 3, p. 485-497, mar. 2010.

VIEGAS, D. X. et al. O complexo de incêndios de Pedrógão Grande e concelhos limítrofes, iniciado a 17 de junho de 2017. Centro de Estudos sobre Incêndios Florestais, ADAI/LAETA. Coimbra, out. 2017. 238 p.

ZHANG, B.; PENG, J.; LI, S. Covering location problem of emergency service facilities in an uncertain environment. Applied Mathematical Modelling, [s.1.], v. 51, p. 429-447, nov. 2017.

ZHANG, Y. J.; LI, A. J.; FUNG, T. Using GIS and multi-criteria decision analysis for conflict resolution in land use planning. Procedia Environmental Sciences, [s.l.], v. 13, p. 2264-2273, 2012. 